\title{
GLL
}

Geomatics, Landmanagement and Landscape No. 4 • 2019, 171-181

\section{MAP CHARTS: VISUALISATION OF STATISTICAL DATA ON A BACKGROUND MAP - CASE STUDY}

\section{Karol Król}

\begin{abstract}
Summary
Data visualizations take a variety of forms, from classic bar charts to three-dimensional presentations on globe maps. The purpose of this paper is a comparative analysis of selected techniques for visualizing statistical data on a background map. The exploratory tests were carried out to study the design possibilities of three software tools: Visualization: GeoChart, GIS and JavaScript and 3D Maps (MS Office), as well as the functionality and usability of applications created with them. In addition, selected technical attributes of the applications were measured, including the size and number of component files, loading time in the web browser window, as well as performance. It has been shown that the tested tools are predisposed to create data visualizations on administrative maps, that they have different design possibilities, that they differ in the degree of service advancement, and that they can also be useful in creating small visualizations, so-called "ad-hoc map".
\end{abstract}

\section{Keywords}

data visualization • geovisualization $\bullet$ online maps $\bullet$ ad-hoc maps $\bullet$ mashups

\section{Introduction}

Information resources are growing at a breakneck pace. At the same time, this information is not somewhat solidified or frozen in the vastness of libraries, university institutes, military staffs, or stock exchanges and banks; instead, information remains in a constant motion [Lem 1999]. Among this information overload, recipients expect new, attractive forms of data presentation that will facilitate the interpretation and assimilation of the message. The era of visual media is a response to the way in which recipients conceptualize reality, i.e. they assimilate and remember more effectively when the message is a combination of words and images [Szews 2014]. The graphic presentation of the data appeals to the imagination and is universal. It evokes emotions and is more easily remembered. It communicates ideas more effectively than rows of numbers. That is why various data visualization techniques, which effectively and efficiently affect the recipients, are gaining in importance [Król 2017]. 
Visualization is information in the form of an image that communicates the content of a message by using shapes, lines, hierarchies, and systems. The purpose of visualization is primarily a graphic presentation of data, facilitating their assimilation and understanding. Visualizations can also be used as a research tool to explore data sets [Piekarski 2015].

Web applications are most typically created using programming languages (PHP, JavaScript, Java), libraries (OpenLayers, jQuery) or complex open source components (GeoServer, PostgreSQL, PostGIS) [Delipetrev et al. 2014]. The development of graphical user interfaces and the availability of software applications in a web browser window have made interactive data visualizations available to users without specialist knowledge. Increasingly numerous tools are at their disposal, enabling them to independently create and publish attractive data visualizations. The latter take various forms, ranging from traditional bar charts to map charts and dashboards. These techniques and tools are widely used in the visualization of various data, including statistical data.

Along with the development of design techniques and tools, new forms and formats of data presentation have appeared, in particular online, interactive and on a map-based. What determines the success of information transfer via the Internet is the functionality of the website. and its individual components. The attractiveness of maps published online is primarily due to the functionality of the medium itself, and the speed of access to geographical information by means thereof [Kowalski 2005]. The usability and functionality of geoinformation services is largely dependent on the technology used, although the imagination and skills of the designer and programmer are also important. The purpose of this paper is a comparative analysis of selected techniques of interactive statistical data visualization on a background map.

\section{Material and methods}

The design possibilities of selected techniques and tools as well as the functionality and usability of visualizations created with their help were subjected to a comparative analysis (Table 1). The basis for the analysis consisted in ad-hoc exploratory tests, which are also sometimes referred to as "expert testing" or "monkey testing" [Afzal et al. 2009, Chhabra 2012]. Design techniques and tools were selected to give an overview of design alternatives.

Ad-hoc exploration tests are informal in their character, and they are performed without pre-planned cases of usage, but with a designated purpose [Itkonen and Mäntylä 2014]. They are often accompanied by improvisation, which makes them difficult to reproduce. The advantage of exploratory tests is their cognitive function. They allow you to become familiar with the specifics of the application being tested, not necessarily described in detail in the design documentation. The test scenario of such tests provides for observing and recording the behaviour of the application in typical conditions in which it operates, i.e. during the implementation of design assumptions or activities performed by users [Król 2016]. Ad-hoc tests were conducted during the creation and use of the application created according to the adopted design assumptions. 
Table 1. Design techniques and tools subjected to exploratory tests

\begin{tabular}{|l|l|l|}
\hline \multicolumn{1}{|c|}{ Design tool } & \multicolumn{1}{c|}{ Design techniques and tools } & Type of map background \\
\hline $\begin{array}{l}\text { Visualization: GeoChart } \\
\text { Region GeoCharts }\end{array}$ & $\begin{array}{l}\text { HTML, CSS, SVG, VML, JavaScript, Google } \\
\text { Visualization API }\end{array}$ & SVG or VML \\
\hline $\begin{array}{l}\text { GIS and JavaScript } \\
\text { ImageMapster } \\
\text { Maplight }\end{array}$ & $\begin{array}{l}\text { QGIS, HTML Image Map Plugin } \\
\text { DHTML: HTML, CSS, jQuery JavaScript }\end{array}$ & Raster file \\
\hline 3D Maps & Microsoft Office Excel & Bing Maps \\
\hline
\end{tabular}

Source: Author's own study

\subsection{Design assumptions}

The main design assumption was to create a map chart, i.e. an interactive visualization of statistical data in the form of a cartogram. The cartogram is a thematic map showing the values of the selected attribute of surface objects that were created by dividing a given area. Object boundaries are predetermined, e.g. by administrative division, whereas attribute values corresponding to objects are presented graphically, e.g. by colour, usually taking into account the ranges of variability of a given attribute.

The project assumes that the cartogram will present the population of individual regions or provinces (voivodeships) in Poland. Statistical data provided by the Central Statistical Office of Poland [GUS 2019] were adopted as input data. In addition, it was assumed that visualization is intended to be a component of a website. At the same time, an attempt was made to obtain a similar form of publication with the aid of each of the tested tools. Next, in the "desktop" mode, selected technical attributes of the application were measured, including: size and number of component files, loading time in the web browser window, as well as overall performance (Table 2).

Table 2. Attributes of the applications and calculation tools

\begin{tabular}{|l|l|l|l|}
\hline \multicolumn{1}{|c|}{$\begin{array}{c}\text { Application } \\
\text { attribute }\end{array}$} & \multicolumn{1}{|c|}{$\begin{array}{c}\text { Measurement } \\
\text { tool }\end{array}$} & \multicolumn{1}{|c|}{$\begin{array}{c}\text { Unit } \\
\text { of measurement }\end{array}$} & \multicolumn{1}{c|}{$\begin{array}{c}\text { Location } \\
\text { of measurement }\end{array}$} \\
\hline Page size & Pingdom & Kilobytes $(\mathrm{KB})$ & Frankfurt, Germany \\
\hline Requests & Pingdom & Number of resource references & Frankfurt, Germany \\
\hline Load time & Pingdom & Seconds (s) & Frankfurt, Germany \\
\hline YSlow & GTmetrix & Percentage points $(0-100)$ & Vancouver, Canada \\
\hline Performance grade & Pingdom & Points $(0-100)$ & Frankfurt, Germany \\
\hline Score & Dareboost & Percentage points $(0-100)$ & Paris, France \\
\hline Speed Index & Dareboost & Points & Paris, France \\
\hline
\end{tabular}

* It is assumed that the value of the Speed Index should oscillate around 1000 units [Król 2018b].

Source: Author's own study 
The performance assessment took into account the values of the following indices: YSlow (YSlow analyses web pages and why they're slow based on Yahoo! Rules for high performance web sites), Page Speed Score (Pingdom Tools) and Speed Index [Król 2018a]. The Speed Index is the average time at which visible parts of the page are displayed. It is expressed in milliseconds and dependent on size of the view port.

\subsection{Characteristics of the analysed designing techniques}

Google Visualization API (Google Visualization Application Programming Interface) is one of the most popular and generally available tools in the world that allows presenting data in the form of interactive map charts [Zhu 2012]. The Visualization API is a set of JavaScript classes called and presented in the structure of a hypertext document. A geochart is a map of a country, a continent, or a region with areas identified in one of three ways: the region mode colors whole regions, such as countries, provinces, or states. The markers mode uses circles to designate regions that are scaled according to a value that you specify. The text mode labels the regions with identifiers. Google Charts are a tool for presenting data in a browser window, whereas the Visualization API is a technique for generating them [Google Charts 2019]. A geochart is rendered within the browser using SVG or VML, and is not scrollable or draggable; also, it's a line drawing rather than a terrain map. The terms of use of the Google API are described in detail in the license terms (Google APIs Terms of Service).

An alternative to the presentation of data using the Visualization API is a presentation created using HTML Image Map Plugin (extension of the QGIS program). This tool transforms vector objects into raster graphics, which is accompanied by a hypertext document [Król 2016]. This document contains vertex coordinates related to specific pixels. The use of jQuery scripts allows you to "animate" these objects.

The first jQuery release was made available in 2006. The library quickly gained recognition and became one of the most popular technologies used to create web applications. JQuery's advantages lie in its relatively simple implementation, easy modification, as well as functionality [Król and Szomorova 2015].

For the preparation of graphs illustrating numerical data, a spreadsheet is most often used. Excel (Microsoft Office) can be used by scientists for dealing with data management problems, ranging from simple tasks to complicated scenarios. There is an underappreciation for the wide diversity of data management tasks that can be handled by Excel and VBA [Rubin et al. 2010]. Microsoft 3D Maps for Excel (Excel 2016, Office $365)$ is a three-dimensional (3-D) data visualization tool. Data are placed on the map based on geographical coordinates, zip codes, or names of localities, countries, regions etc. [Winston 2016]. Designing visualizations is done entirely using a graphical user interface. Data are presented on the Bing map (Bing Maps). Users have at their disposal maps of the whole globe, and various themes, i.e. graphical forms of map presentation and a large spectrum of chart configuration. 


\section{Results of exploratory testing}

The end result of using Visualization: GeoChart is an interactive map chart presented in a web browser window (Fig. 1). After hovering over objects located on the map, information placed in a "pop-up" window is presented. The map background is dynamically generated in this case (SVG or VML). It is slightly different in the case of a cartogram created with the help of GIS and JavaScript tools (Fig. 2). The essential part of the visualization is the raster file, which is "scripted". Also in this case, the information is presented in a separate window, which is a permanent element of the visualization.

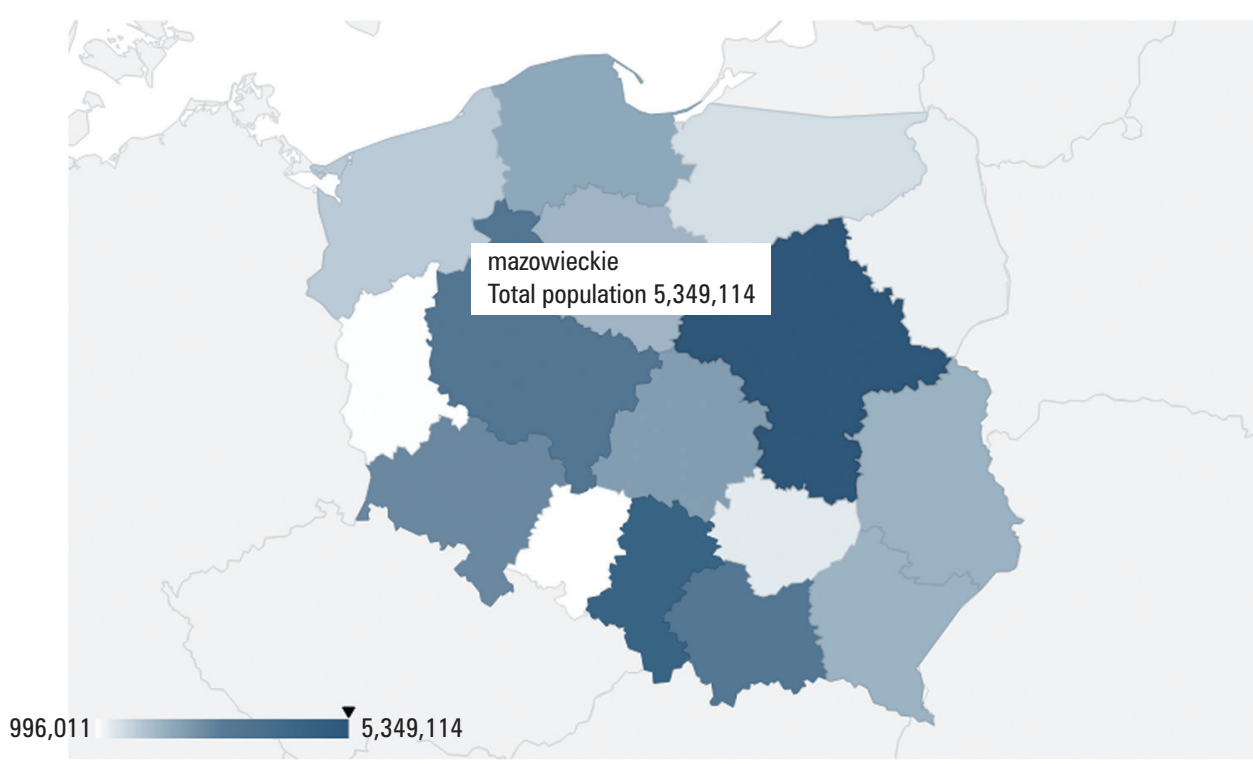

Source: Author's own study using Visualization: GeoChart

Fig. 1. Visualization: Region GeoCharts - a sample of an interactive thematic map - total population, subdivided by regions/provinces (voivodeships) in Poland; screen shot

The limitation of the 3D Maps tool is the inability to save the map as a hypertext document. Visualizations created in 3D Maps can be saved in a raster format (Fig. 3), i.e. as graphic files, or in the form of animations, i.e. video clips, the so-called visual guide (MP4 files). Information assigned to objects located on the map is displayed in the popup window only at the design stage.

The 3D Maps application requires Internet access because it uses Bing Maps. Dynamic map size change in 3D Maps is possible only at the design stage (Table 3). None of the tools support digital zoom of the map view, or allow to grab and drag the map area. The presentations obtained in this way are "closed" and limited to a selected part of the map. 


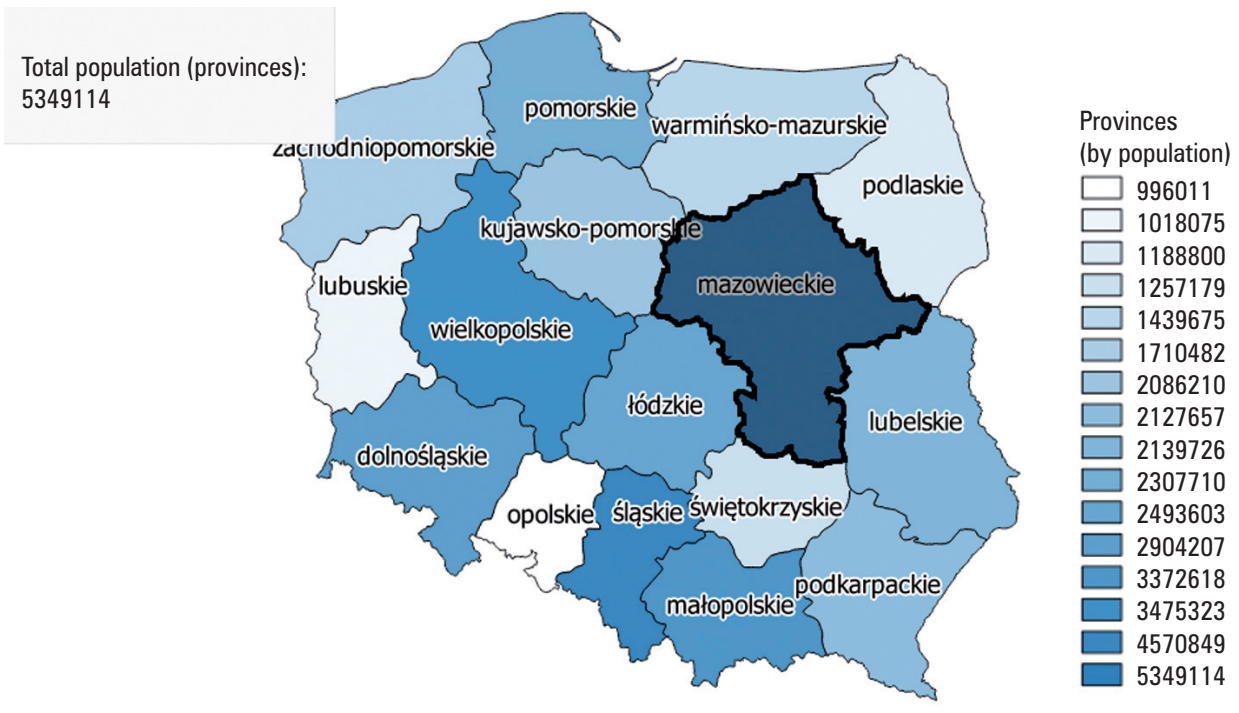

Source: Author's own study using QGIS Image HTML Map Plugin software and JavaScript

Fig. 2. A sample of thematic map - total population, subdivided by regions/provinces (voivodeships) in Poland; screen shot

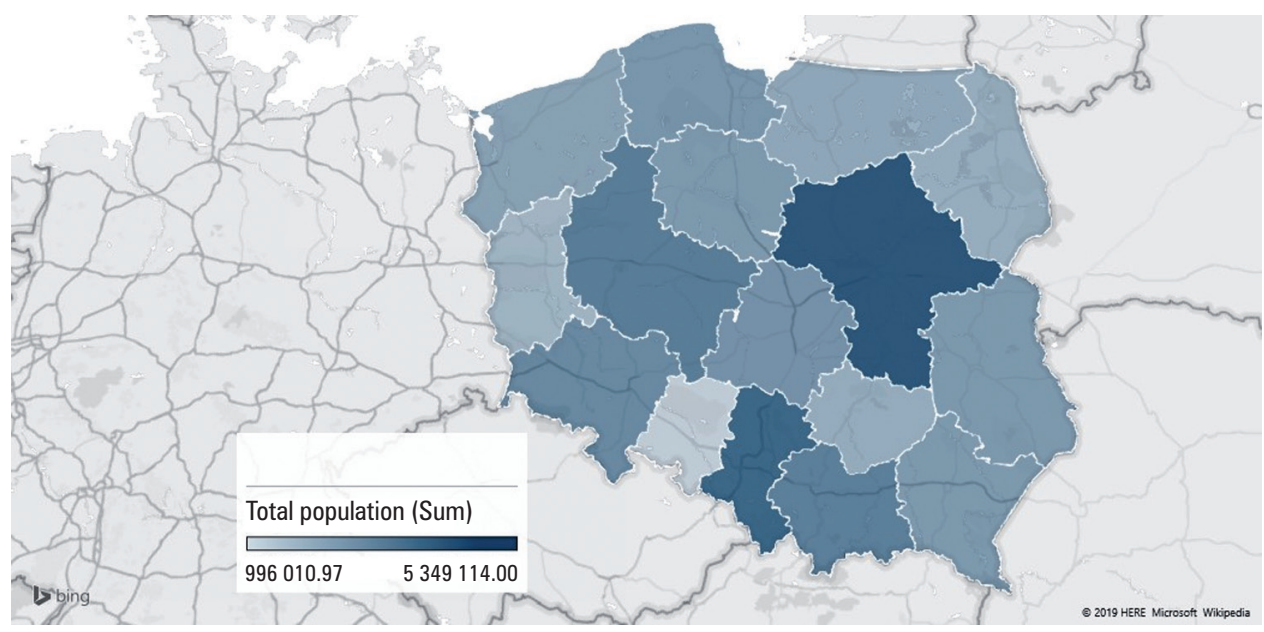

Source: Author's own study using 3D Maps (Microsoft 3D Maps for Excel)

Fig. 3. 3D Maps - a sample of thematic map - total population, subdivided by regions/provinces (voivodeships) in Poland; raster file

The performance of the created applications is comparable, although it is difficult to treat the component-only performance in absolute terms. After all, these are some kind of "partial presentations". These types of applications, which take the form of small 
components, are most often presented on websites as their fragments, components, content supplementation, or data visualization. Such small components will not significantly affect the performance of the websites where they are located. Equally important in this case may be the "requests" and "page size" attributes, which measurably determine the specific "weight" of the component or the load that it can generate for the parent site (Table 4).

Table 3. Comparison of applications' functionalities

\begin{tabular}{|l|c|c|c|}
\hline \multicolumn{1}{|c|}{ Visualisation attribute } & Region GeoCharts & GIS and JavaScript & 3D Maps \\
\hline Marking the area with the mouse cursor & - & - & - \\
\hline Map as a tool for data analysis & - & - & + \\
\hline End product & $\begin{array}{c}\text { SVG or VML map/ } \\
\text { HTML/JS }\end{array}$ & HTML/JS/raster & raster/video \\
\hline Format of presentation & dynamic & static/dynamic & $\begin{array}{c}\text { static/ } \\
\text { video/3D }\end{array}$ \\
\hline Works offline & $+/-\left(^{*}\right)$ & + & $+/-(\wedge)$ \\
\hline Shapes of administrative regions & + & - & + \\
\hline Heat map, bar charts, pie charts, others & - & - & + \\
\hline Dynamic change of map size & - & + & - \\
\hline Map key & + & + & + \\
\hline Navigation & + & - & - \\
\hline Drag and drop - viewing the map area & - & - & - \\
\hline Digital zoom & - & + & - \\
\hline
\end{tabular}

${ }^{\star}$ ) Provided that all constituent elements of the visualisation are stored in one data carrier.

$(\wedge)$ In its end format, i.e. a raster or a video file.

Source: Author's own study

Table 4. Comparison of selected technical attributes of the applications

\begin{tabular}{|l|c|c|c|}
\hline Visualisation attribute & Region GeoCharts & GIS and JavaScript & 3D Maps \\
\hline Page size (KB) & 400.3 & 189.4 & 474.5 \\
\hline Requests (incl. scripts) & $12(8)$ & $6(2)$ & $3(0)$ \\
\hline Load time (s) & 0.9 & 1.8 & 1.8 \\
\hline YSlow & 85 & 90 & 97 \\
\hline Performance grade & 85 & 94 & 99 \\
\hline Dareboost & 70 & 70 & 73 \\
\hline Speed Index & 1334 & 851 & 1000 \\
\hline
\end{tabular}

Source: Author's own study 
The large number of references to external resources is unfavourable, as is the large volume of component files. Research conducted in 1997 showed that the main reason for the slow loading of contemporary websites were large graphic files. Currently, slow loading of websites is usually caused by server delays, by too many components used, including those from external sources, and by excessively "fancy" widgets [Nielsen 2010].

\section{Limitations of the tested tools and practical implications}

Usability tests performed in the Mozilla Firefox web browser window and using the Opera Mobile Emulator application have shown that none of the applications is adapted to the use on mobile devices. Yes, it is possible to view such visualizations on the screen of a smartphone, for instance, but it can be difficult. The website whose graphic design adapts itself to the display size (resolution dependent layout) was presented for the first time in 2004. Responsive web design (RWD) puts the user's needs and comfort of browsing the website at the centre. RWD technology assumes smooth scaling of website content while maintaining image quality and simplicity of navigation.

It is not possible to indicate which tool is the best among those tested. However, it is possible to indicate which tool is best for specific applications/uses. When only static map presentation is expected, e.g. in the form of graphics, 3D Maps is the simplest solution. In many cases involving data visualization, 3D Maps eliminates the need for programming altogether, letting you work directly with your data in a spreadsheet and see relationships right on a map [Au and Rischpater 2015]. When the project provides for map interactivity, it is worth reaching for Visualization: GeoChart, while when the user has a GIS database available, you can use HTML Image Map Plugin to transform it into a map component.

Tested tools differ in the level of sophistication of the service. It is worth paying attention to the time of cartogram development and the degree of difficulty of its preparation. 3D Maps is a tool supported by a graphical interface known from MS Office software. The user obtains the expected effect using the keys. In the first phase of design work, the dynamics and interactivity of the Bing Maps are impressive, but the end result is a raster or video file. They may prove insufficient for the implementation of the adopted design assumptions. 3D Maps, therefore, allows for advanced data analysis, but the basic form of publishing the results is a graphic file. In turn, Visualization: GeoChart is a programming interface (API). Changing map attributes, e.g. colours or spatial range, requires at least basic programming skills, as well as knowledge of the basics of HTML and CSS. The use of Visualization: GeoChart requires working with code. The same is true for maps created using GIS tools. Programming the interactivity of maps generated in this way requires JavaScript. The availability of tools may also be a limitation. While Visualization: GeoChart and the QGIS application are available free of charge, 3D Maps is a fee-based tool, although the program is also available in a test version, free of charge.

The tested tools are predisposed to creating data visualizations on administrative maps: of countries, regions or provinces (voivodeships), districts (poviats) etc. However, 
the quality and availability of the administrative division may differ. Using the tools that we subjected to testing, it is possible to make thematic maps, for instance, advanced visualizations of the results of analyses, or spatial phenomena (Fig. 4). However, these tools can be most helpful when creating small visualizations, the so-called "ad-hoc maps".
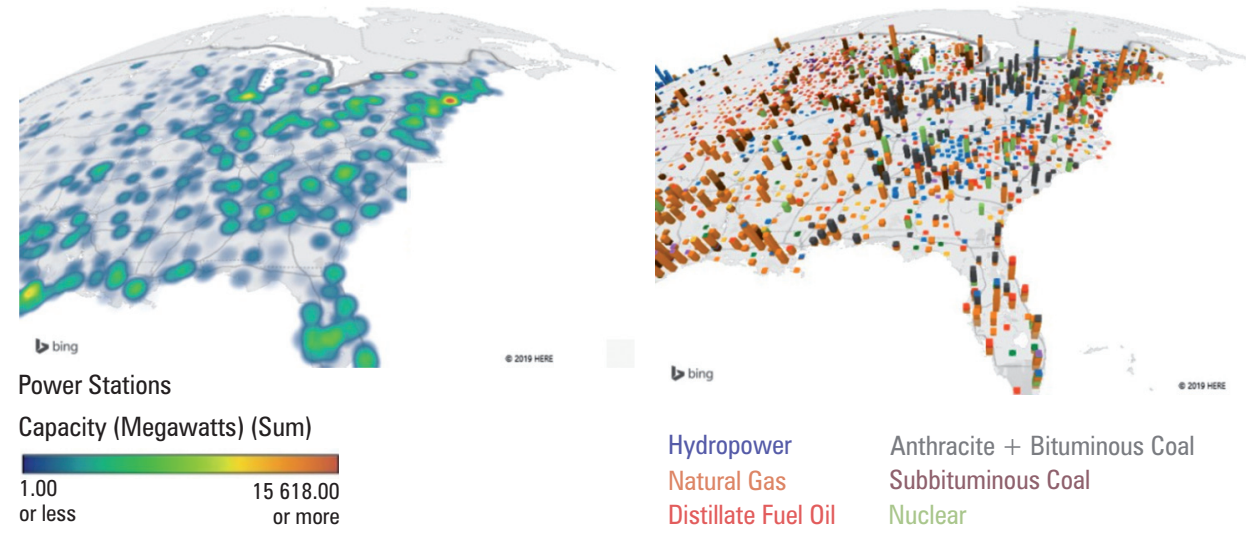

Source: Author's own study using 3D Maps (Microsoft 3D Maps for Excel)

Fig. 4. Map of a power plant, case study from the USA - heat map and bar charts on the map, screen shot

Maps or visualizations of the "ad-hoc" kind are made on expediency basis, "for now", when there is no need to create advanced map services, when there is a lack of funds for a specialized map service, or when a quick presentation of the phenomenon on the map is needed. Then the 3D Maps tool may be the most effective, especially if the given map is to be a supplement to the printed textual report.

\section{Conclusions}

The main difference between the tested tools occurs at the design stage, i.e. the development of the "final product" or cartogram. The end result is also different. The 3D Maps application is a data analysis tool. It allows visualizing different parts of data on one map. Similar possibilities are offered by the QGIS application used to generate the map in "GIS and JavaScript" technology. In contrast, Visualization: GeoChart is a tool for visualizing data that has already been pre-developed.

The end result in the form of a cartogram obtained with the help of each tool is apparently similar, but significantly different in terms of implementation. The map creation method is also completely different. The user will notice, above all, differences in the interactivity and presentation of the cartogram, including the map key, and pop-up windows. Map created with Visualization: GeoChart is a component of 
a hypertext document. Its implementation requires knowledge of HTML and CSS, and the creation of a map requires knowledge of Google Visualization API. Creating a map with the help of QGIS Image HTML Map Plugin and JavaScript requires similar skills, although in this case the knowledge of using GIS desktop applications is also required. The raster resulting from the transformation of the map created in 3D Maps is the simplest in terms of implementation.

\section{References}

Afzal W., Torkar R., Feldt R. 2009. A systematic review of search-based testing for non-functional system properties. Inf. Softw. Technol., 51 (6), 957-976.

Au C., Rischpater R. 2015. Power Map for Excel. [In:] Microsoft Mapping. Geospatial Development in Windows 10 with Bing Maps and C\#. Ed. C. Au, R. Rischpater. Apress, Berkeley, CA, 159-165.

Chhabra M.N. 2012. Introduction to Adhoc Testing. International Journal of Scientific and Technology Research, 1 (7), 66-67.

Delipetreva B., Jonoskia A., Solomatineb D.P. 2014. Development of a web application for water resources based on open source software. Computers \& Geosciences, 62, 35-42.

Google Charts 2019. Visualization: GeoChart. Interactive charts for browsers and mobile devices. https://developers.google.com/chart/ [accessed: 29.04.2019].

GUS2019.Ludnośćwedługwojewództw. GłównyUrządStatystyczny.https://stat.gov.pl/statystyka -regionalna/rankingi-statystyczne/ludnosc-wedlug-wojewodztw/ [accessed: 29.04.2019].

Itkonen J., Mäntylä M.V. 2014. Are Test Cases Needed? Replicated Comparison Between Exploratory and Test-Case-Based Software Testing. Empirical Software Engineering, 19 (2), 303-342.

Kończak G. 2014. Rola graficznych prezentacji danych w popularyzacji statystyki. Wiadomości Statystyczne, 7, 49-61.

Kowalski P.J. 2005. Funkcjonalność geoinformacyjnych witryn internetowych. Roczniki Geomatyki, III (2), 77-87.

Król K. 2016. Data Presentation on the Map in Google Charts and jQuery JavaScript Technologies. Geomat. Landmanag. Landsc. (GLL), 2, 91-106.

Król K. 2017. Analiza porównawcza wybranych technik interaktywnej prezentacji danych. Studia Ekonomiczne. Zeszyty Naukowe Uniwersytetu Ekonomicznego w Katowicach. Informatyka i Ekonometria, 342, 86-98.

Król K. 2018a. Comparative analysis of the performance of selected raster map viewers. Geomat. Landmanag. Landsc. (GLL), 2, 23-32.

Król K. 2018b. Performance threshold of the interactive raster map presentation - as illustrated with the example of the jQuery Java Script component. Geographic Information Systems Conference and Exhibition GIS Odyssey, 321-327.

Król K., Szomorova L. 2015. The possibilities of using chosen jQuery JavaScript components in creating interactive maps. Geomat. Landmanag. Landsc. (GLL), 2, 45-54.

Lem S. 1999. Bomba megabitowa. Wydawnictwo Literackie, Kraków.

Nielsen J. 2010. Website Response Times. Nielsen Norman Group. https://goo.gl/MymMco [accessed: 29.04.2019].

Piekarski K. 2015. Siedem rzeczy, które musisz wiedzieć, zanim zabierzesz się do wizualizacji danych. [W:] Metody badania i odkrywania miasta oparte na danych. Red. K. Piekarski. Medialab, Katowice, 12-21. 
Rubin A.E., Russo M.F., Neil W. 2010. Using Microsoft Excel ${ }^{\circledR}$ as a Laboratory Data Management Tool. Pharmaceutical Sciences Encyclopedia: Drug Discovery, Development, and Manufacturing, 8, 1-49.

Szews P. 2014. Liczby, dane i statystyki w dziennikarstwie internetowym. Acta Universitatis Lodziensis. Folia Litteraria Polonica, 1 (23), 247-263.

Winston W. 2016. Microsoft Excel data analysis and business modeling. Microsoft Press, Redmond, Washington, USA.

Dr inż. Karol Król

Uniwersytet Rolniczy w Krakowie

Katedra Gospodarki Przestrzennej i Architektury Krajobrazu

30-059 Kraków, al. Mickiewicza 24/28

e-mail:k.krol@onet.com.pl

website: http://homeproject.pl

ORCID: https://orcid.org/0000-0003-0534-8471 